\title{
Mysterious cecal polypoid mass
}

\author{
Firas Kadurei BMsc, Jaber Al-Ali MD FRCPC
}

\section{CASE PRESENTATION}

A 52-year-old man presented with a longstanding history of recurrent, colicky-like, central abdominal pain. A computed tomography scan of the abdomen revealed a well-defined, hyperdense lesion, $2.5 \mathrm{~cm} \times$ $2.3 \mathrm{~cm}$ in size, with fat density apparent at the ileocecal junction. The patient subsequently underwent a colonoscopy in which a large $2.5 \mathrm{~cm}$ $\times 2.5 \mathrm{~cm}$ colonic polypoidal mass was apparent, partially then fully protruding from the ileocecal valve (Figures $1 \mathrm{~A}$ and $\mathrm{B}$ ). The protruded mass was then pulled back to its original position and was no longer visible. A referral to the surgical team was made and the mass was removed laparoscopically. Histopathology demonstrated the mass to be a tubular adenoma of low-grade dysplasia within the terminal ileum.

\section{DISCUSSION}

Intussusception in the present case occurred when the pathological lesion protruded through the ileocecal valve pulling part of the area attached to it, which led to the telescoping of one part into the other.
As a result, a relatively common site of intussusception is the ileocecal area (1). Many are associated with a pathological lesion, which can be malignant or benign (2). It occurs rarely in adults, and presents with a variety of nonspecific symptoms, making its preoperative diagnosis difficult. Most patients present with symptoms of obstruction similar to the patient in the present case. Most often, preoperative diagnosis includes imaging studies, with computed tomography imaging being the most recently used, which show characteristic findings of 'target signs' enabling the radiologist to make a correct diagnosis (3). Occasionally, an intussusception may be confirmed by colonscopic evaluation; however, a recent report (4) documented that ileocecal intussusception due to an ileal polyp may be precipitated by colonoscopy and should be included in the differential diagnosis of acute abdomen after colonsoscopy. In adults, operative treatment is usually required because the cause often proves to be malignant. In the present case, the polypoidal mass was defined as a tubular adenoma and subsequently resected operatively.
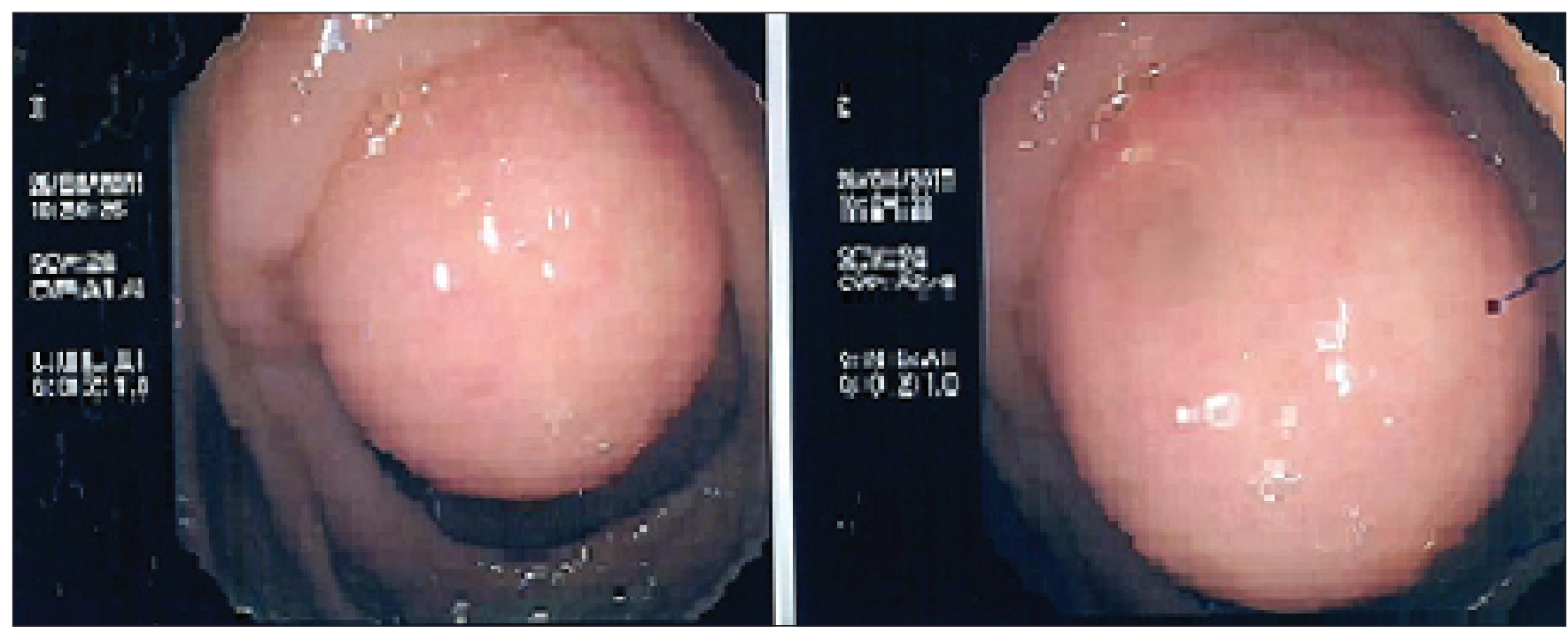

Figure 1) A Partially protruding cecal mass lesion. B Fully protruding cecal mass lesion

\section{REFERENCES}

1. Yakan S, Caliskan C, Makay O, Denecli AG, Korkut MA. Intussusception in adults: Clinical characteristics, diagnosis and operative strategies. World J Gastroenterol 2009;15:1985-9.

2. Azar T, Berger DL. Adult intussusception. Ann Surg 1997;226:134-8.

3. Gayer G, Zissin R, Apther S, Papa M, Hertz M. Adult intussusception - a CT diagnosis. Br J Radiol 2002;75:185-90.
4. Lasithiotakis K, Grisbolaki E, Filis D, Athanasakis I, Zoras O, Chalkiadakis G. Ileocolic intussusception precipitated by diagnostic colonoscopy: A case report. Surg Laparosc Endosc Percutan Tech 2012;22:e161-3.

The Canadian Journal of Gastroenterology is considering a limited number of submissions for IMAGE OF THE MONTH. These are based on endoscopic, histological, radiological and/or patient images, which must be anonymous with no identifying features visible. The patient must consent to publication and the consent must be submitted with the manuscript. All manuscripts should be practical and relevant to clinical practice, and not simply a case report of an esoteric condition. The text should be brief, structured as CASE PRESENTATION and DISCUSSION, and not more than 700 words in length. A maximum of three images can be submitted and the number of references should not exceed five. The submission may be edited by our editorial team.

Department of Medicine, Faculty of Medicine, Kuwait University, Kuwait

Correspondence: Mr Firas Kadurei, Faculty of Medicine, Kuwait University, PO Box 24923, Safat 13110, Kuwait.

Telephone 965-99046731,fax 965-25338907,e-mail firas@hsc.edu.kw

Received for publication November 26, 2012. Accepted November 29, 2012 


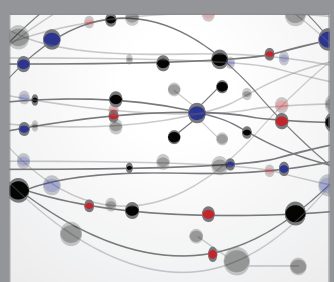

The Scientific World Journal
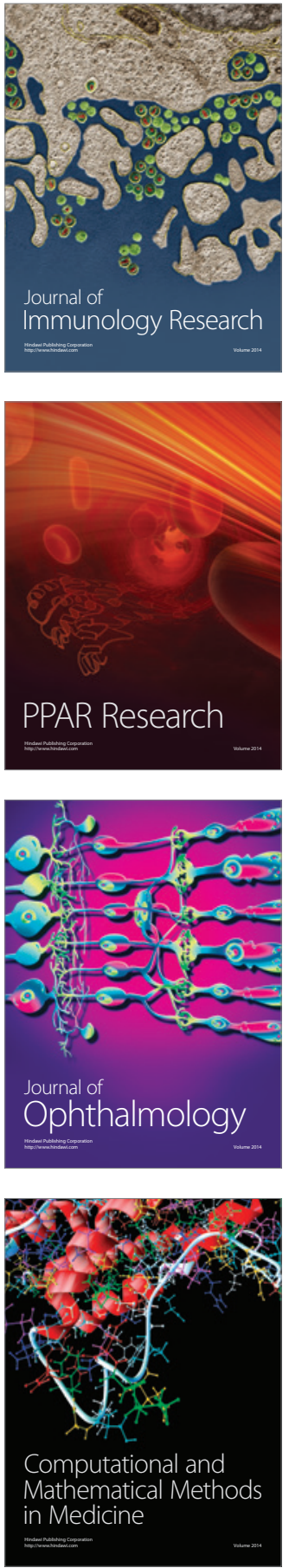

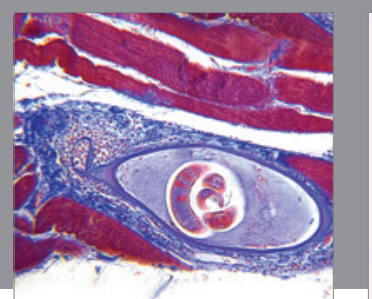

Gastroenterology Research and Practice

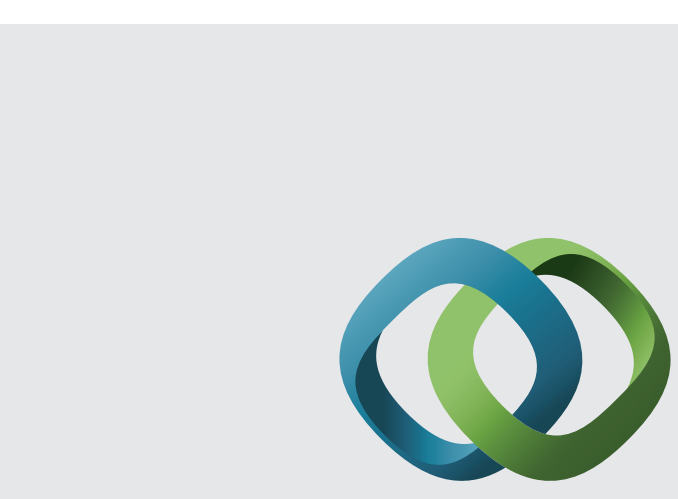

\section{Hindawi}

Submit your manuscripts at

http://www.hindawi.com
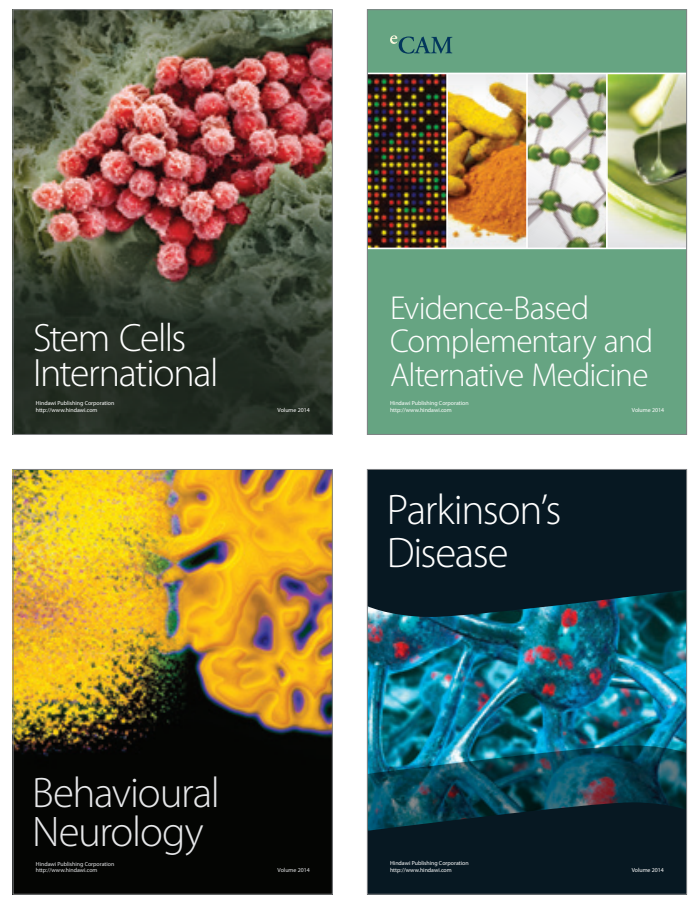
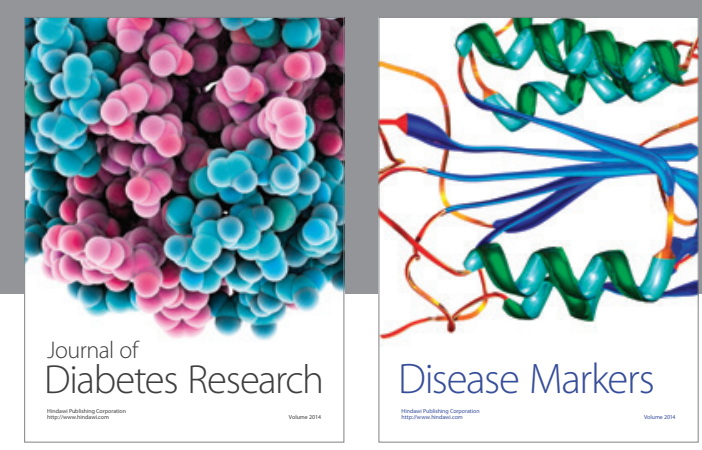

Disease Markers
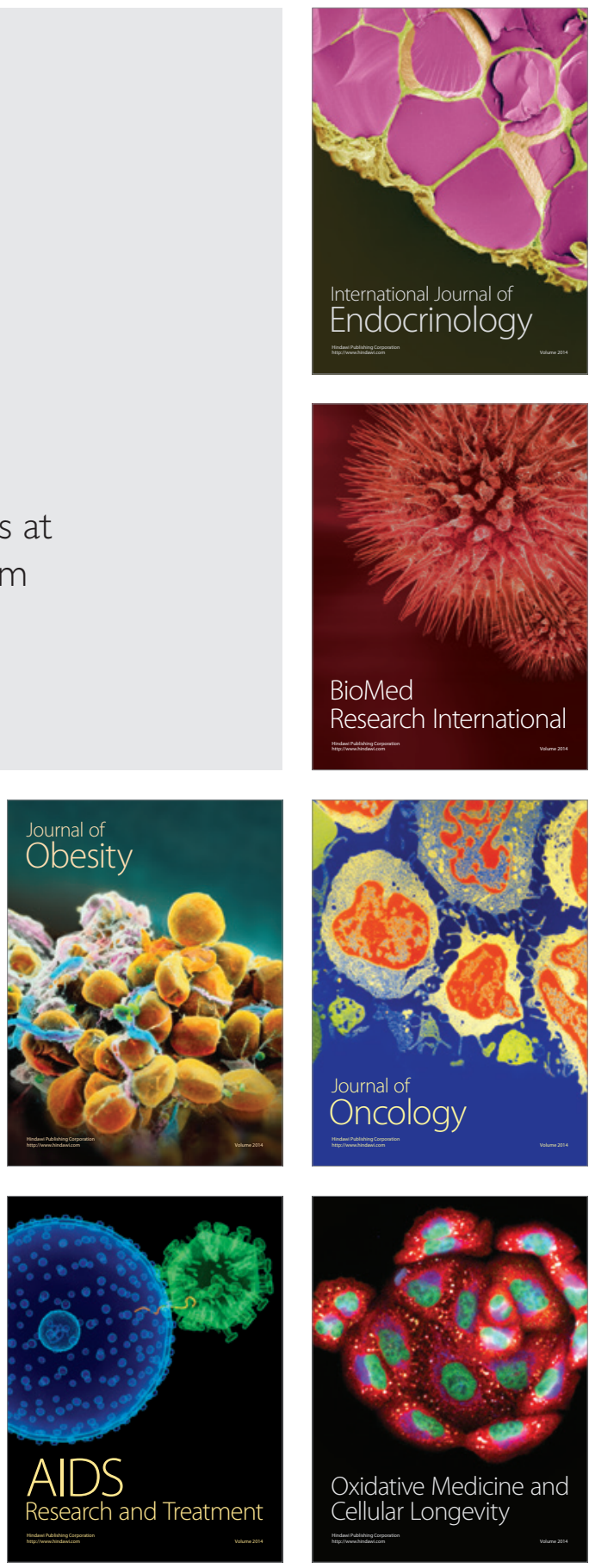